\title{
Theoretical and practical considerations in the treatment of morphofunctional imbalances of dento-maxillary system for the age period after 12 years - preliminary study
}

\author{
Irina Adriana BEURAN ${ }^{1}$, lleana IONESCU ${ }^{1}$, Oana EFTENE ${ }^{1}$, Cosmin MEDAR ${ }^{1}$, \\ Maria Glencora COSTACHE ${ }^{1}$, Corina Marilena CRISTACHE ${ }^{1}$, Liliana BURLIBASA ${ }^{2}$, \\ Stefan PERIEANU ${ }^{1}$, Madalina Violeta PERIEANU ${ }^{1}$, Iuliana BABIUC ${ }^{1}$, Oana Cella ANDREI ${ }^{1}$, \\ Luminita OANCEA $^{1}$, Simion Gheorghe DUMITRU ${ }^{3}$, Gabriela TANASE ${ }^{1}$

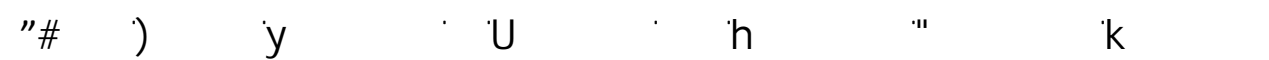

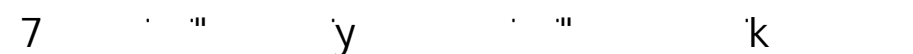

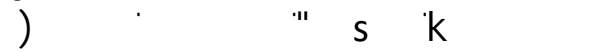

\footnotetext{
ABStract

This age period after 12 years is characterized by an increase in all dimensions of all the anatomical structures of the individuals, under the influence of new factors that interfere with the general tonus of the body.

Purpose. Thus, in this paper, we approached certain aspects of both theoretical and practical that may occur in the formation and development of dento-maxillary system in the age period of 12 years (after some authors, up to the age of 21 years).

Material and method. The study was conducted between May 12 and June 252018 with the help of 55 dental practitioners.

Results and discussions. The analysis of the answers provided by the participants in the study was performed by means of specific research methods. The results are eloquent and provide an overview of how dental practitioners manage the eruption of the wisdom tooth in the developmental processes of the dento-maxillary system.

Conclusions. The eruption of the wisdom tooth is a certain element of growth, which must be taken into account in the future therapeutic approach of the morpho-functional imbalances of the dento-maxillary system.
}

Keywords: morphofunctional imbalances, age after 12 years, dentist, growth age

\section{INTRODUCTION}

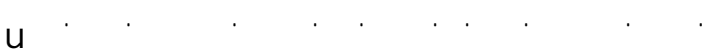

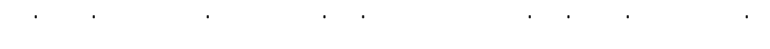
tŚZZ;6T)

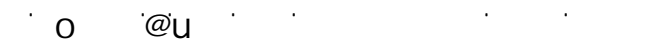

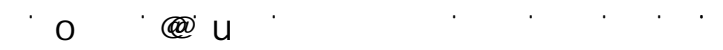

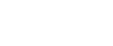

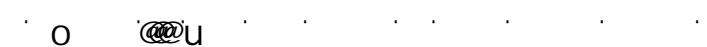

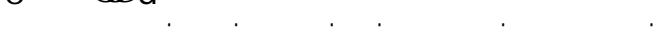

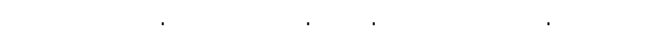
†苔ŶY

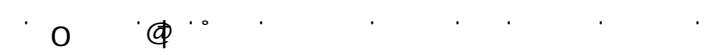

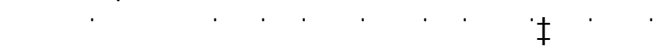

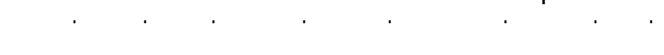

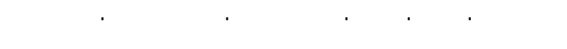


This age period after 12 years is characterized by an increase in all dimensions of all the anatomical structures of the individuals, under the influence of new factors that interfere with the general tonus of the body (and here we discuss the endocrine glands, especially sexual ones) (1-5).

Growth is uneven, with a lack of harmony between segments (disharmony between limb growth and facies). Harmonization of segments usually begins during puberty. The same factors we have mentioned earlier are the factors that drive and increase of dento-maxillary system (1-5).

\section{PURPOSE OF THE STUDY}

This age period, the fourth stage in the growth rythm of individuals, is characterized by providing a sufficient supply of elements needed for the growth and maturation of tissues of any kind. An intense physical activity as well as a sustained brain activity, both of which are important for this age of improving the training of the individual, produce very intense burns to the body, demanding a special energy supply (1-5).

A balance between training activity and physical activity on the one hand and food intake on the other, but also a balance between them and the psychic life that becomes more complex from day to day for subjects over the age of 12 . These are extremely important growth hygiene issues as important to the health of the individual as to the health of the dento-maxillary system (1-5). Specifically, this is the age period when the influence of the social environment on the individual's development takes effect and finally shapes the hereditary and environmental factors (1-5).

Starting from these interesting aspects that are involved in the formation and development of dento-maxillary system in the age period after 12 years, in the following, there is a need for a clear explanation of the notions that characterize this particularly important stage in the growth rythm of individuals, issues which must be known to all dental practitioners, regardless of their specialty and which constitute itself the purpose of this report.

\section{MATERIAL AND METHOD}

Even after the eruption of the 12-year old molars (also known as second permanent molars), both the maxillary and the mandibular, the dento-maxillary system is not completed as structure and development, because an extremely significant element will appear, wisdom tooth (1-5). This is a certain element of growth, which we must take into account in the therapeutic approach of morpho-functional imbalances of the dento-maxillary system for this age period after 12 years.

Thus, the eruption modalities of the wisdom tooth are very different and particularly unstable both as morphology, neighborhood relations, but also as a period of eruption and are accompanied by other events that characterize the dento-maxillary apparatus at this age, namely the explosion of caries with an evolutionary tendency, very aggressive and with the characteristics of a systemic disease symmetrically placed on the homologous teeth (they are closely related to the growth contidioning, the imbalances between intense energy consumption and food intake are not always adequate) (1-5).

The dental pathology of age period after 12 years obliges the dentist to pay very special attention to both diagnostically and prognostically, and of the therapeutic attitude. It is in fact the age when the decrease of the body's resistance capacity allows the exacerbation of some germs virulence, triggering inflammatory processes, the age when marginal periodontitis occurs, as a result of microbial imbalance in favor of the pathogenic flora (1-5).

At the same time, in this age period, the relationship between the teeth are not yet stable and may be unbalanced by (1-5):

- the shape of the important elements as a position, modified by a carious lesion on the occlusal and/or contact surface, to which is added the stimulation of the growing wisdom tooth;

- a minimal edentation that does not draws the patient attentio, but which, along with what happens distally, leads to important changes in relationship between teeth.

The eruption in step of the mandibular wisdom tooth (due to the absence and/or dwarfism of the maxillary wisdom tooth and distalized relationship of the mandible) causes an obstacle in the lateral and diagonal movements of the mandible with unbalanced effects on the periodontal tissue (we discuss in fact about the phenomenon described by Thielleman) (1-5). The eruption vices of the mandibular wisdom tooth can cause a further imbalance factor within the dento-maxillary system, through the pushing process of the 12-year-old molar towards mesial. Thus, taking into account all the possibilities of negatively influencing the relationship between the constituents of this dento-maxillary system produced by the wisdom tooth, it is mandatory to monitor the position of the germs and their possibility of eruption in rela- 
tion to what is found mesial of them (1-8). The distalization of mandible, which is seen as the most frequent dimensional change, is aggravated by odontal pathology (1-5). In general, many of these extremely important aspects connected to the 12-year-old molar that we have previously presented can only be highlighted with high quality imaging examinations.

The attitude of the dentist after the age of 12 must be well defined and clarified. In this regard, the dentist will intervene quickly and rigorously in the treatment of dental caries, applying the principles stated by C.V. Black to avoid relapse and secondary caries, restoring properly the morphology of the tooth. Regarding the prosthetic treatment of edentation, it is necessary to consider the general characters of the growth and the eruption of the wisdom tooth (1-5). Also after the age of 12, the doctor may also intervene in dento-alveolar disharmonies, regardless of their nature, acting on the maxillary (up to the age of 16) and on the mandible (up to the age of 21) or intervening on the positioning and structuring of the periodontium, through the eruption of the wisdom tooth (1-5, 9-17).

In the conservative therapy, special attention will be paid to the protection of pulpal connective tissue because at this age the healthy pulpal tissiue is capable of defense (1-5). At the same time, it is very important to continue the functional hygiene by educating the activity of dento-maxillary system (articulation, speech, breathing, etc.) and helping the self-cleaning function with a very rigorous hygiene (1-5).

Events in the dento-maxillary system are the result of previous age events and fall into the future, therefore a systematic activity at school age (active school follow up care between the ages of 6-12 years) will determine another state of the dento-maxillary system than the one currently encountered, and will greatly change the future of this system (dento-maxillary) at the adult level (1-5).

Thus, the dento-alveolar pathology of this age period after 12-year-old is very difficult, due to the diversity of the major aspects that morpho-functional imbalances could embrace (1-5).

In order to carry out this study, we have developed a questionnaire consisting of 7 questions, applied to 55 dental practitioners in Bucharest (simple dentists, resident doctors, specialists in: general dentistry, dental prosthodontics, orthodontics and dentofacial orthopedics, pedodontics, endodontics, dental surgery, periodontics, oral and maxillofacial surgery). Subjects were aged between 29 and 53 and showed the following gender distribution: 42 of the subjects were female $(76.36 \%)$, while the remaining 13 subjects were male (23.64\%) (Fig. 1). The study was conducted between May 12 and June 25, 2018.

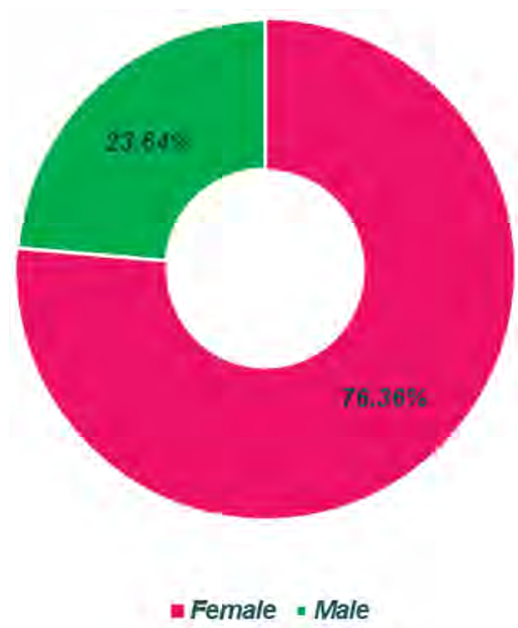

FIGURE 1. Gender distribution of the study group

Next, we will present the questionnaire applied to the 57 subjects:

\section{Questionnaire}

1. How do you assess the influence of the wisdom tooth eruption in the formation and development of the dento-maxillary system in the age period afte 12-year-old? A. Of increased importance; b. Average importance; c. Irrelevant?

\section{Correct answer: a}

2. The rapid increase with evolving trend of caries, very aggressive and with characteristics of a systemic disease, symmetrically placed on the homologous teeth that occurs in patients over the age of 12 years are closely related to? a. Some growth as well as imbalances between intense consumption and inappropriate food intake conditioning. b. Dysfunction of all endocrine factors. $c$. An increased pace of growth and physical and intellectual development of individuals?

\section{Correct answer: $\boldsymbol{a}$.}

3. The age after 12 years is the time when the resistance of the body decreases, as follows: a. It allows to exacerbate the virulence of some germs that trigger inflammatory processes. $b$. Marginal periodontal inflammation begins as a result of a break in microbial balance in favor of pathogenic flora. c. The ecological balance of the oral cavity is changed, through the penetration of highly aggressive microbial species through food intake.

\section{Correct answers: $\boldsymbol{a}, \boldsymbol{b}$.}

4. Distalization of the mandible, which is seen as the most frequent dimesional change, is aggravated by: a. Rapid extraction of the wisdom teeth. 
b. Odontal pathology. c. Strong dysfunctions of the phonetic function.

\section{Correct answer: $\boldsymbol{b}$.}

5. How do you think the dentist's attitude toward patients aged over 12-years-old should be defined? a. Will intervene quickly and rigorously in the treatment of dental decay, applying the recommended principles, to avoid relapse and secondary caries, and correct rebuilding the morphology of the tooth; $b$. The prosthetic therapy in the reconstruction of the edentation must take into account the general characters of the growth and eruption of the wisdom tooth; $c$. Will have a cautious and awaiting attitude, both for odental treatments and for prosthetic treatments?

\section{Correct answers: $\boldsymbol{a}, \boldsymbol{b}$.}

6. How do you think the orthodontist should intervene in dento-alveolar disharmonies in patients over the age of 12 years: a. Act on the jaw until the age of 16 years. $b$. Act on the mandible until the age of 21 years. c. Interferes with the positioning and structuring of the periodontium, because of the wisdom tooth eruption. $d$. Does not perform any specialized interventions until the age of 21 years.

\section{Correct answers: $a, b, c$.}

7. Regarding functional hygiene for patients over 12-years-old, the following aspects should be considered: a. Continue functional hygiene by educating dento-maxillary system activity (articulation, speech, breathing, etc.). b. Ensure that the self-cleaning function is supplemented by a very rigorous hygiene. $c$. Insist on visits as often as possible to the dentist, at least once a month, in order to ensure the functional hygiene of the patient.

\section{Correct answers: $a, b$.}

\section{RESULTS}

The responses provided by the 55 participants were systematized as follows:

40 of the practitioners $(72.73 \%)$ consider that the eruption of the wisdom tooth as a phenomenon in the process of formation and development of the dento-maxillary system has an increased importance, 10 practitioners (18.18\%) consider it to be of medium importance while only 5 practitioners (9.09\%) consider it to be irrelevant (Fig. 2).

Regarding the rapid increase with very aggressive evolving trend of caries 49 of the subjects consider it to be closely related to some growth conditioning, 4 subjects as being related to the dysfunction of all endocrine factors and 2 subjects as related to a high rhythm of growth and physical development (Fig. 3).

About the decreasing resistance of the body in the age period after 12-years-old, all respondents to this study offered the correct answers (variants $a$ and $b)$.

Precocious extractions of the wisdom tooth are considered by 5 participants $(9.09 \%)$ of the study to be the cause that aggravate the mandible distalization. For the same problem, the rest of the participants in the study (50 - representing 90.91\%) provided the correct answer, namely the odontal pathology (Fig. 4).

For the fifth question related to how to define the attitude of the dentist towards patients with age over 12-years-old, most of the specialists involved in the study (52 representing 94.55\%) responded correctly, variants a and b, while only 3 practitioners (representing 5.45\%) have responded wrongly (Fig. 5).

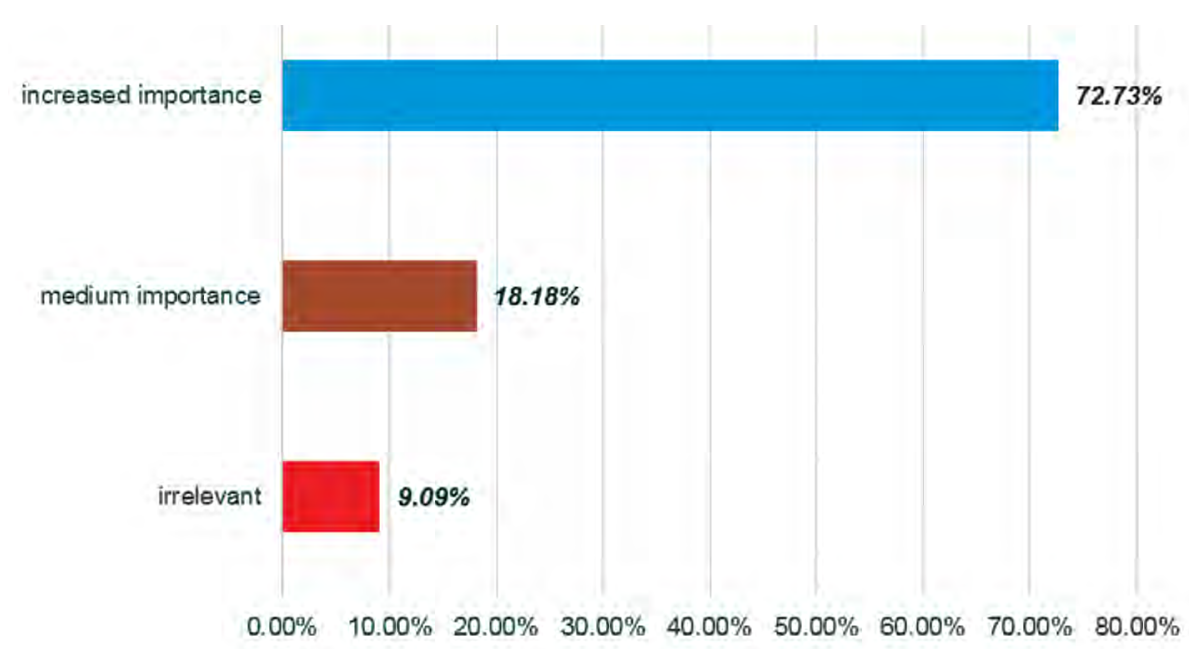

FIGURE 2. Influence of wisdom tooth eruption in the process of formation adn development of the dento-maxillary system 


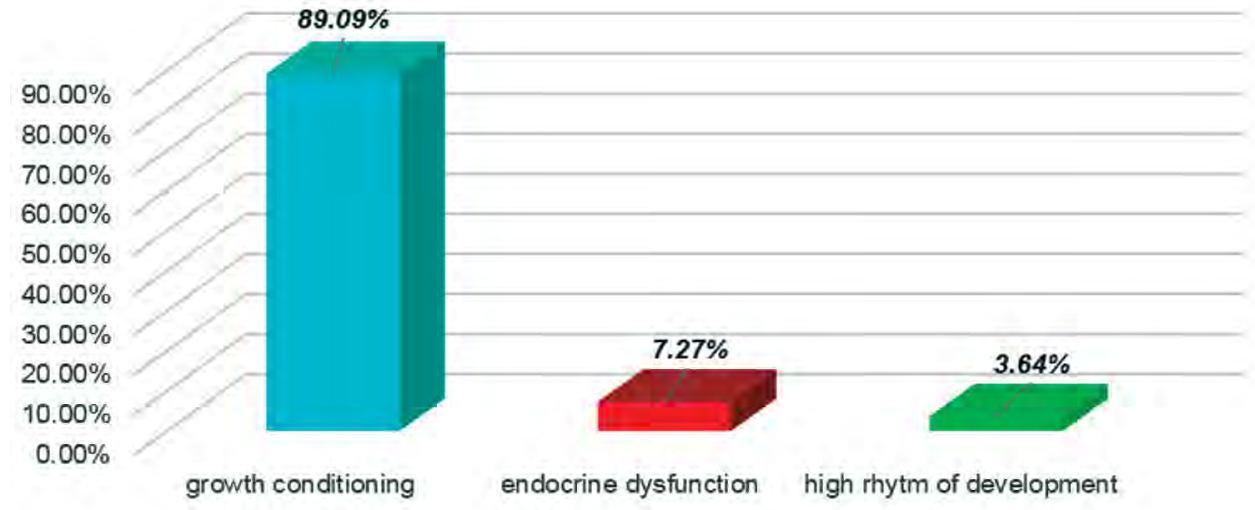

FIGURE 3. Etiology of phenomena that occurs in patients over the age of 12 years

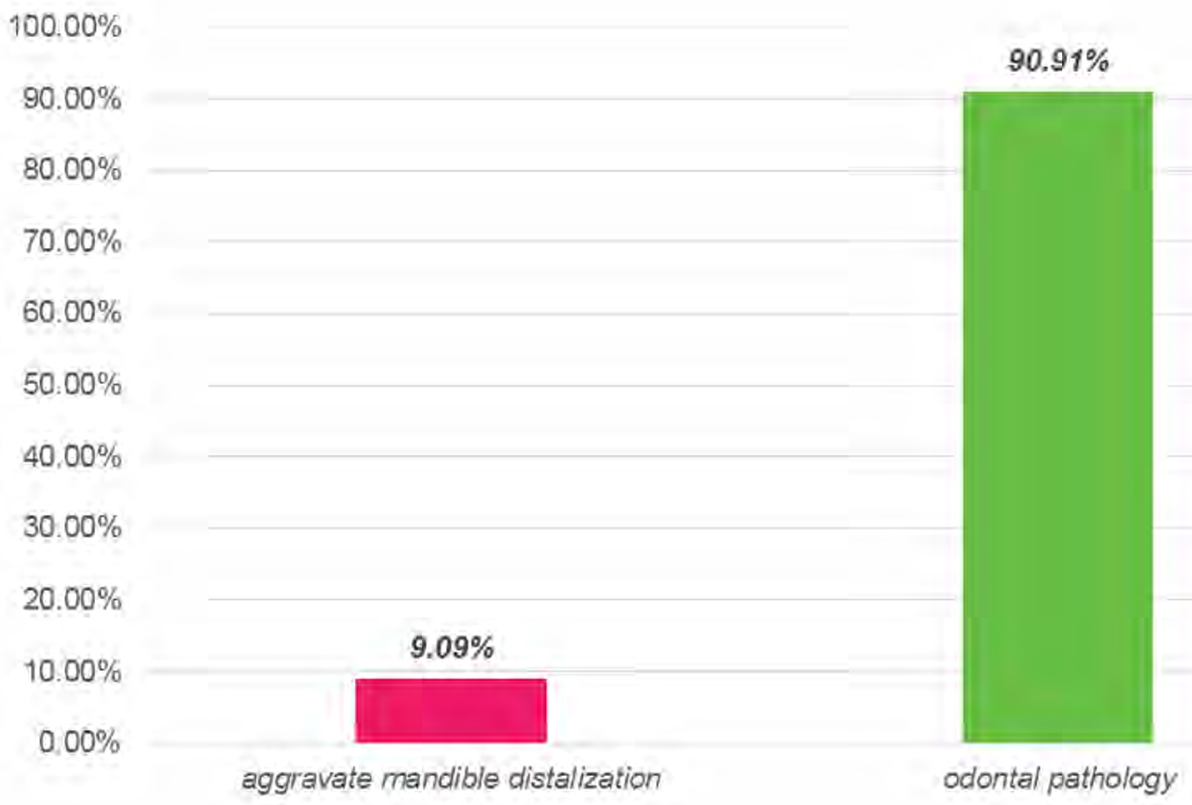

FIGURE 4. The effect of wisdom tooth precocious extraction

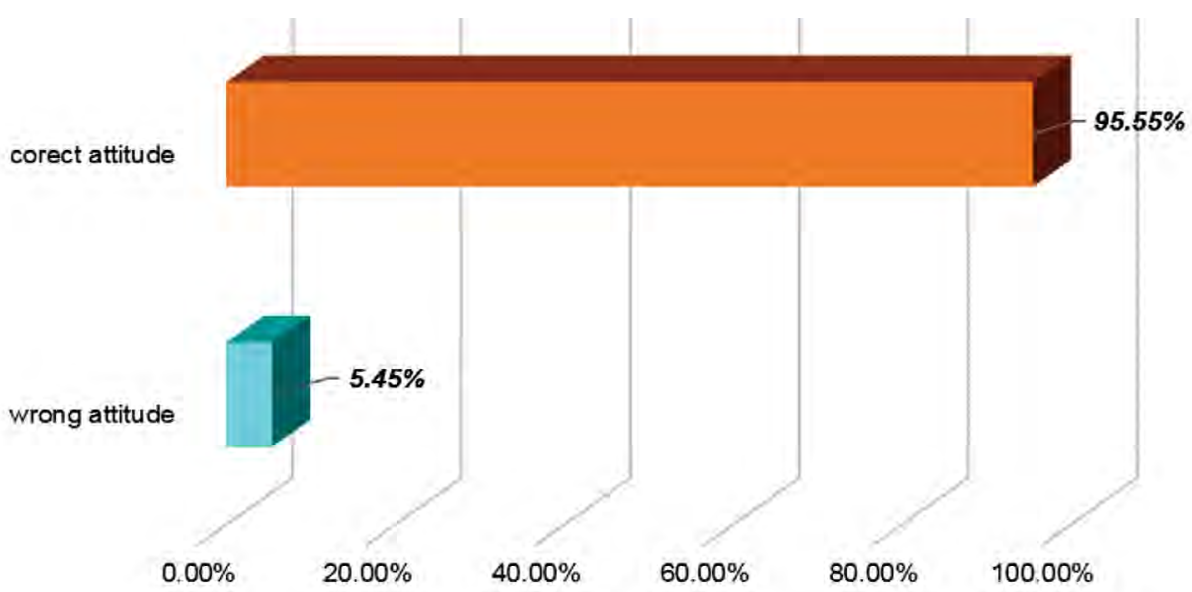

FIGURE 5. Dentist's attitude toward patients aged over 12-years-old 
The last two questions regarding the intervention of the orthodontist in dento-alveolar disharmonies, respectively the aspects related to functional hygiene for patients over 12-years-old, all respondents in this study provided the correct answers $(a, b$ and $c$ for the 6th question, respectively $a$ and $b$ for the 7 th question).

\section{CONCLUSIONS}

The eruption of the wisdom teeth is a certain element of growth, which must be taken into account in the future therapeutic approach of morpho-functional imbalances of detno-maxillary system for this age period after 12-years-old.

The increasing number of caries with a highly aggressive evolutionary tendency and with the characteristics of a systemic disease symmetrically placed on the homologous teeth, usually following the eruption of wisdom tooth, are related both to growth conditioning, but also to the imbalances between intense consumption and inappropiate food intake, in terms of quality and required components. Thus, a demineralizing diet, determined by a food habit, does not compensate for the plastic needs of the dental tissues, but only provides the energy coverings of the physical effort. If we add to these causes and the fact that the dento-maxillary system is not morphologically and functionally intact (see the effects of earlier periods), the new growth factors will influence the final picture of this age, which is noticeable on the

reports between the constituent elements of the dento-maxillary system (occlusion and articulation), on the teeth positioning, but also on the trophicity of the odontal and periodontal tissues.

The dentist who intervenes in the treatment of patients aged over 12-years-old must have a technically complex formation both in terms of surgical conservative therapy and in the context of the predominant conjunctive restoration therapy being considered as the most pretentious form of therapy. At the same time, the dental practitioner is asked, as far as possible, for a pedodontic training, which sees the growing dento-maxillary system.

The dentist who carries out dental treatments for patients with age over 12-years-old must take into account the activities of this age in all their complexity and therefore the lack of time of the young people. Health care and dental-maxillary system care should be part of the general training of young people and, in order to be more effective, should be linked to the community.

Specifically, all dentists, regardless of their specialty, who work mostly with patients over the age of 12 years, must master the elements that provide long term results both in the rehabilitation of the functional form of the teeth, in the prosthetic therapy, but also in the dento-alveolar rebalancing therapy.

\section{Acknowledgement}

In this article, all the authors have equal contribution with the first author.

Conflict of interest: none declared Financial support: none declared

\section{REFERENCES}

1. Miyasaki-Ching CM. Elemente clinice de stomatologie. București: Ed. All, 2001.

2. Gall II. Asistența stomatologică. București: Ed. Didactică și Pedagogică, 1971.

3. Rosenstiel SF, Land MF, Fujimoto J. Contemporary fixed prosthodontics. $4^{\text {th }}$ ed. St. Louis: Mosby Elsvier, 2006.

4. Anusavice KJ. Dental materials. Philips' Science $11^{\text {th }}$ ed. St. Louis: Saunders Elsvier, 2003.

5. Pătrașcu I. și colab. Materiale dentare Lucrări practice. București: Ed. Horanda Press, 2002.

6. Burlibasa L, Zarnescu O. In vivo effects of Trichostatin A - a histone deacetylase inhibitor on chromatin remodeling during Triturus cristatus spermatogenesis. Anim Reprod Sci 2013, 142 (1-2): 89-99.

7. Gavrila L, Mircea L. Chromatin and chromosomal fine structure in spermatogenesis of some species of amphibians. Zygote. 2001, 9(3): 183-192.

8. Cristache $\mathrm{CM}$, Burlibasa $\mathrm{M}$, Cristache $\mathrm{G}$ et al.. Zirconia and its biomedical applications. Metalurgia International. 2011; Vol. XVI, No. 7: 18-23.
9. Burlibasa M, Muntianu LAS, Tănase G et al. Study on microbial contamination of biomaterials in medical practice. Metalurgia International. 2010; Vol. XV, Spec. Iss. 2: 163-166.

10. Burlibasa M., Cristache C.M., Georgescu S.R. et al. Toxicity of titan and nikel-cobaltchromium alloys. Metalurgia International. 2009, 14: 20-22.

11. Burlibasa L, Gavrila L. Chapter 6 Developmental epigenetics: roles in embryonic development. In: Niculescu MD, Haggarty P. Nutrition in Epigenetics. Willey-Blackwell Publishing 2011: 105-126.

12. Cristache $C M$., lonescu $C$, Cristache $G$ et al. A 5-year prospective randomised clinical trial on the efficiency of two different attachement systems as retention for implant-supported mandibular overdenture. Radiographic assesment, cost analysis and final evaluation of treatment, $s$ success. Metalurgia International. 2009; Vol. XIV, Spec. Iss. No. 16: 27-34.

13. Cristache CM, Ionescu C, Burlibasa $M$ et al. Retentive anchors versus magnets as attachment systems for mandibular overdenture. A 5-year prospective randomised clinical study. Metalurgia International. 2009; Vol. XIV, Spec. Iss. No. 16: 59-64.

14. Tănase G, Burlibasa M, Muntianu L et al. Testing the antibacterial potential of biomaterials in medical practice. Metalurgia International. 2010; Vol. XV, Spec. Issue No. 2: 160-162.

15. Burlibasa M, Cernusca-Mitariu M, Burcea $\mathrm{CC}$ et al. Halogen compounds - theoretical, physiological and practical aspects regarding the decontamination, disinfection and sterilisation of intsruments and biomaterials in dental medicine practice. Metalurgia International. 2013; Vol. XVIII, Spec. Issue No. 3: 54-57.

16. Burlibasa L., Domnariu C. Epigenetic landscape of human diseases. Acta Medica Transilvanica. 2018; 23(2): 33-37.

17. Bodnar DC, Burlibasa L, Varlan C et al. Mercury, biocompatibility and its impact on environment. Metalurgia International. 2009; 14: 95-100. 